\title{
Exfoliation Technique of Composing and Depictions of Clopidogrel Bisulphate Afloat Microspheres
}

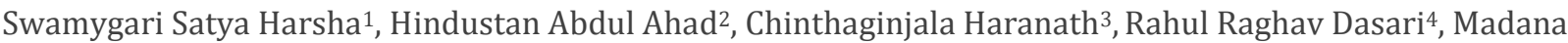 \\ Gowthami $^{5}$, Naga Jyothi Varam ${ }^{6}$, Samhitha Rao Bitranganti' , Gamaa Birir Mohamed Musa ${ }^{8}$
}

${ }^{1}$ Department of Pharmaceutics, RIPER- Autonomous, Ananthapuramu, Andhra Pradesh, India. ${ }^{2}$ Department of Industrial Pharmacy, RIPER- Autonomous, Ananthapuramu, Andhra Pradesh, India. ${ }^{3}$ Department of Industrial Pharmacy, RIPER- Autonomous, Ananthapuramu, Andhra Pradesh, India. ${ }^{4}$ Department of Industrial Pharmacy, RIPER-

Autonomous, Ananthapuramu, Andhra Pradesh, India. ${ }^{5}$ Department of Industrial Pharmacy, RIPER- Autonomous, Ananthapuramu, Andhra Pradesh, India. ${ }^{6}$ Department of Industrial Pharmacy, RIPER- Autonomous, Ananthapuramu, Andhra Pradesh, India. ${ }^{7}$ Department of Industrial Pharmacy, RIPER- Autonomous, Ananthapuramu, Andhra Pradesh, India. ${ }^{8}$ Department of Industrial Pharmacy, RIPER- Autonomous, Ananthapuramu, Andhra Pradesh, India.

\section{ABSTRACT}

\section{BACKGROUND}

Gastro retention dosage forms are obligatory for holding the drug in the stomach for area definite drug discharge by afloat technique. Floating microspheres (FM) of Clopidogrel Bisulphate (CB) were fabricated to increase the drug's reach to blood and to show elongated drug release.

\section{METHODS}

FM of CB were prepared by the ion gelation (exfoliation) method using ethyl cellulose, carrageenan gum, and sodium alginate. The drug-loaded FM were designed and assessed for their physicochemical characteristics including drug-excipient friendly behaviour by Differential Scanning Calorimetry (DSC) and Fourier Transform InfraRed (FTIR)

\section{RESULTS}

The DSC and FTIR study revealed the compatibility of CB with the excipients used. The percentage yield of FM from all formulations was good and showed satisfactory buoyancy and floating time. \% CB release for the formulations was found up to $98.5 \%$ (F8) till $10^{\text {th }}$ hour. The release kinetics revealed that CB discharge from the devices was best fitted to Hixson Crowell's model with regression values ranging from 0.887 to 0.989 .

\section{CONCLUSIONS}

FM with CB can be formulated using sodium alginate, ethyl cellulose and carrageenan gum by exfoliation gelation method.

\section{KEY WORDS}

Clopidogrel Bisulphate, Carrageenan, Buoyancy, Discharge
Corresponding Author: Dr. Hindustan Abdul Ahad, Professor and HOD, Department of Industrial Pharmacy, Raghavendra Institute of Pharmaceutical Education and Research (RIPER)-

Autonomous, Anathapuramu-515721, Andhra Pradesh, India.

E-mail: abdulhindustan@gmail.com

DOI: $10.14260 / j e m d s / 2020 / 251$

Financial or Other Competing Interests: None.

How to Cite This Article:

Harsha SS, Ahad HA, Haranath C, et al. Exfoliation technique of composing and depictions of clopidogrel bisulphate afloat microspheres. J. Evolution Med. Dent. Sci. 2020;9(14):1156-1160, DOI: $10.14260 / \mathrm{jemds} / 2020 / 251$

Submission 22-01-2020,

Peer Review 14-03-2020,

Acceptance 21-03-2020,

Published 06-04-2020. 


\section{BACKGROUND}

The abundant dosage forms available in the market are of oral as they are said to be safe, expedient, litheness, handling, and wide acceptance by the patients. Retaining the dosage form at the stomach is gaining fascination by the researchers owing to its local action or discharge.

The floating drug delivery system (FDDS) is designed for gastrointestinal retention for a long duration. ${ }^{1}$ The FDDS offers a beneficial volume of a drug at the appropriate site and then to preserve the expected drug levels all over the delivery period. A foremost pitfall of oral systems is the uneven absorption of the drug in all the regions of GIT. Multiple doses required for conventional oral systems for maintaining the uniform drug concentration. The attainment of the drug from the delivery system hinges on the degree of absorption through GIT. So, the knowledge of attaining drug absorption demanded in emerging of the Gastro retentive drug delivery system (GRDDS). Gastro retaining of solid dosage forms can be attained by the contrivances of altered density, mucus adhesion, expansion, and unfolding, etc.

The approach of microencapsulation makes all range of drugs like solids/liquids/gases, which can be encircled in a suitable thin coat of polymers. Microspheres are size ranged $<1000 \mathrm{~m}$. They are more impressive, as they flow freely, upgraded bioavailability, good entrapment, reduced side effects, and the polymers used in them are of biodegradable behavior. Floating Microspheres (FM) which were prepared with low-density (less than gastric fluids) polymers, which can be retained at the site (stomach) for a sufficiently long time, that makes and becoming interesting for many researchers in these dosage forms.

Clopidogrel Bisulphate (CB), inhibits P2Y12 adenosine $5^{\prime}$ diphosphate (platelet receptors) and shows its anti-platelet activity $^{2}$ used to constrain blood clots in a diversity of circumstances like peripheral vascular issues and clots in coronary artery/cerebral arteries. $\mathrm{CB}$ acts on the ADP receptor on the membrane of the platelets. Carboxyl Clopidogrel is activated from Clopidogrel pro-drug by cytochrome P450 (liver) and CYP2C19, leads in diminished cross-linking of the protein fibrin. CB has a $\mathrm{t} 1 / 2$ of $\sim 8 \mathrm{~h}$ and performs by creating a disulfide channel with the platelet receptor ADP. CB is absorbed orally and reaches only to its half owing to deprived water solubility. $\mathrm{CB}$ has reported side effects like gastric haemorrhage and $\mathrm{CB}$ resistance through continuing therapy. Controlled release of floating CB need is anticipated for a number of reasons viz., better bioavailability and diminished side effects like gastric bleeding, less chance to attaining drug resistance, results in improved patient acquiescence.

The present objective of this investigation was to develop CB exploring FM was primed by exfoliation technique using sodium alginate, Ethyl Cellulose, and carrageenan gum. The intention of this study to retain the formulation and release of $\mathrm{CB}$ in the stomach for a sufficiently long time in the targeted region. The prepared FM were explored for their size, the incorporation of efficiency, the buoyancy. The in-vitro release and kinetics of $\mathrm{CB}$ discharges from the microspheres.

\section{METHODS}

\section{Material}

Clopidogrel Bisulphate was gifted by Apotex, Bangalore. Sodium alginate, Ethyl Cellulose, Carrageenan, and Calcium chloride were of Fischer Chemic Ltd, Hyderabad. Double distilled water was used when desired during the work. The slant of equipment involved were digital balance (Vibra Technologies, Bangalore), magnetic stirrer (Remi, Secunderabad), melting point apparatus (Sisco Ltd. Hyderabad), DSC scanner (Perkin Elmer, USA), FTIR (Bruker Alfa II), UV visible spectrometer (Shimadzu-S1210), membrane filter (millipore), probe Sonicator (power sonic, Mumbai) and dissolution test apparatus (Electro Lab USP TDL081).

\section{Drug Excipient Compatibility Studies}

Before fabricating the formulation, the feasibility of $\mathrm{CB}$ with the polymers used can be ascertained by DSC and FTIR studies.

\section{Differential Scanning Calorimetry (DSC)}

The DSC analyses of CB and formulation blend were performed with the DSC apparatus. Each sample was positioned in an aluminum pan discretely with heating rates of $10^{\circ} \mathrm{C} / \mathrm{min}$ from $50-300{ }^{\circ} \mathrm{C}$ under nitrogen environment, with a flow rate of 50 $\mathrm{ml} / \mathrm{min}$

\section{FTIR Study}

Typical peaks of $\mathrm{CB}$ and $\mathrm{CB}$ with an excipient blend were obtained by an FTIR spectrophotometer.

\section{Preparation of FM}

The FM of the CB was prepared by the exfoliation technique. The sodium alginate cross-linking polymers were immersed in water for $24 \mathrm{~h}$. The CB has taken in water $(10 \mathrm{ml})$ dissolved and then assorted with the polymer mixture. Later the solution was poured slowly using a 24-gauge syringe into calcium chloride (15\%) solution. The formed FM was left for $30 \mathrm{~min}$ in the resulted solution with stirring to complete the reaction and to form spherical MS.3-5 the prepared MS were strained, splashed with distilled water and finally dried in an oven at $45^{\circ} \mathrm{C}$. The dried MS preserved in an airtight container. The contents of the MS were charted in Table 1.

\begin{tabular}{|c|c|c|c|c|c|c|c|c|}
\hline \multirow{2}{*}{ Ingredients } & \multicolumn{10}{|c|}{ Formulations } \\
\cline { 2 - 10 } & F1 & F2 & F3 & F4 & F5 & F6 & F7 & F8 \\
\hline Clopidogrel Bisulphate & 75 & 75 & 75 & 75 & 75 & 75 & 75 & 75 \\
\hline Sodium alginate & 10 & 20 & 30 & 10 & 20 & 30 & 10 & 20 \\
\hline Ethyl Cellulose & - & - & - & 10 & 20 & 30 & 10 & 20 \\
\hline Carrageenan (\%) & 5 & 5 & 5 & 10 & 10 & 10 & 15 & 15 \\
\hline Calcium chloride (\%) & 3 & 3 & 3 & 3 & 3 & 3 & 3 & 3 \\
\hline
\end{tabular}

\section{Characterization of FM}

Determination of Entrapment Efficiency

To determine the incorporation efficiency, $100 \mathrm{mg}$ of FM were taken, carefully ground and suspended in $\mathrm{HCl}(0.1 \mathrm{~N})$. Subsequently, the contents suspended in the water were maintained by probe sonication (power sonic 505) for $20 \mathrm{~min}$ and stirred with a magnetic agitator (Remi) for the whole extraction of the CB from the FM. The subsequent solution was clarified through a $0.45 \mu$ membrane filter (millipore). The CB was dogged by a UV-visible spectrophotometer (Shimadzu- 
S1210) at $254 \mathrm{~nm}$. The entrapping percentage was calculated using the following formula. ${ }^{6}$

Drug entrapment efficiency $=\frac{\text { Experimental drug content }}{\text { Theoretical drug content }} \times 100$

Particle Size Distribution

Particle size analyses of the FM were performed by sieve analysis in a sieve shaker ${ }^{7}$ with the help of sieve sets ranged from \# 16, \#20, \#30, \#40, \#60 and \#80.

\section{Buoyancy Percentage}

The FM (0.3 g) was placed in USP XXIV, type II- dissolution apparatus occupied with $900 \mathrm{ml}$ of 0.1 molar $\mathrm{HCl}$ with a surfactant-Tween $80(0.01 \%)$. The medium was enthused at $100 \mathrm{rpm}$ for $12 \mathrm{~h}$. The floating and a stabilized portion of the FM was recovered separately. The FM were withered and pondered. The buoyancy rate was premeditated as the proportion of the bulk of the FM that endured fluctuating and the total mass of the $\mathrm{FM}^{8}$. The percent float was assessed by the given formula.

$\%$ Buoyancy $=\frac{\text { Weight of the FM }}{\text { Weight of the settled FM }} \mathrm{X} 100$

In Vitro Release Studies

CB discharge from prepared FM done by the USP basket dissolution rate test device. FM of the required quantity was suspended in $900 \mathrm{ml}$ of $\mathrm{HCl}(0.1 \mathrm{M}$ of $\mathrm{pH} 1.2)$. The medium was enthused $(100 \mathrm{rpm})$ and upheld at $37 \pm 0.5^{\circ} \mathrm{C}$ by maintaining sink conditions ${ }^{9}$. After adequate dilution, the samples were analysed for quantification of the $\mathrm{CB}$ at $254 \mathrm{~nm}$ using the Shimadzu UV-VIS dual-beam spectrophotometer.

\section{Mechanism of Release}

The mechanism of $\mathrm{CB}$ release was estimated by fitting $\mathrm{CB}$ discharge to the various kinetic equations such as zero-order, first-order, Hixson Crowell's and finding the slope (y) and regression $\left(\mathrm{R}^{2}\right)$ values of the release profile corresponding to each model.10-13

\section{RESULTS}

In this investigation, CB floating microspheres were made with Sodium alginate, Ethyl Cellulose, and Carrageenan by exfoliation technique.

\section{Drug-Excipient Compatibility}

The CB thermo gram was characterized by a single acute endothermic started at $159.21{ }^{\circ} \mathrm{C}$, gave an optimum peak at $157.01{ }^{\circ} \mathrm{C}$ and ended at $163.24^{\circ} \mathrm{C}$, on the other hand, the $\mathrm{CB}$ mixture presented the initiation of an endothermic peak at $157.95^{\circ} \mathrm{C}$, optimum at $154.53^{\circ} \mathrm{C}$ and ended at $157.99^{\circ} \mathrm{C}$. These thermo grams indicated that a small change to the left when combined with excipients, this could be owing to the $\mathrm{CB}$ melting or its conversion into an amorphous form. These thermo grams indicate that there are no signs of incompatibility between CB and excipients. The details of the DSC thermo gram are shown in table 2.

\begin{tabular}{|c|c|c|c|c|c|}
\hline \multirow{2}{*}{$\begin{array}{c}\text { DSC } \\
\text { Sample }\end{array}$} & \multicolumn{3}{|c|}{$\begin{array}{c}\text { Endothermic } \\
\text { Events }\left({ }^{\circ} \mathbf{C}\right)\end{array}$} & $\begin{array}{c}\Delta \mathbf{H} \\
\text { Fusion }\end{array}$ & \multirow{2}{*}{ Inference } \\
\cline { 2 - 5 } & $\begin{array}{c}\text { T } \\
\text { Onset }\end{array}$ & $\begin{array}{c}\text { T } \\
\text { Peak }\end{array}$ & Tend & $\begin{array}{c}\text { Enthalpy } \\
\text { (J) }\end{array}$ & \\
\hline CB & 159.21 & 157.01 & 163.24 & -189.69 & An endothermic peak \\
\hline $\begin{array}{c}\text { CB }+ \\
\text { excipients }\end{array}$ & 157.95 & 154.53 & 157.99 & -192.48 & $\begin{array}{c}\text { A shift in peak to left due to } \\
\text { interaction between CB with } \\
\text { excipients used }\end{array}$ \\
\hline \multicolumn{7}{|c|}{ Table 2. DSC Data of Drug and Excipient } \\
\hline \multicolumn{7}{|c|}{} \\
\hline
\end{tabular}

The FTIR spectra of CB showed characteristic stretches of 'OH' group at $3450 \mathrm{~cm}^{-1}$, 'CH'- Stretch at $2954 \mathrm{~cm}^{-1}$, carboxylic ( $\mathrm{c}=0$ ) at $1752 \mathrm{~cm}^{-1}$, etc., which were also seen in FTIR spectrum of CB-excipient blend indicating no possible incompatibility of $\mathrm{CB}$ with the excipients used. The FTIR stretches the values of $\mathrm{CB}$ and its mixture with excipients (table 3 ).

\begin{tabular}{|c|c|c|}
\hline \multirow{2}{*}{$\begin{array}{c}\text { Characteristic Peaks and } \\
\text { Stretches }\end{array}$} & $\begin{array}{c}\text { Frequency } \mathbf{( c m}^{-1} \text { ) } \\
\text { Cisulphate }\end{array}$ & $\begin{array}{c}\text { Clopidogrel Bisulphate } \\
\text { + Excipients }\end{array}$ \\
\cline { 2 - 3 } & 3450 & 3452 \\
\hline OH (Carboxylic) & $2954,3077,3119$ & $2959,3079,3121$ \\
\hline CH Stretch & 2464 & 2480 \\
\hline CS-C stretch & 1752 & 1784 \\
\hline Co carboxylic & 1474,1496 & 1465 \\
\hline Ring stretch & 1439,1383 & 1441,1392 \\
\hline Pyridine methylene wag & 1188 & 1193 \\
\hline C-o carboxylic acids & 1298,1275 & 1297 \\
\hline Methylene twist & 1221 & 1222 \\
\hline C-CI stretch and bend & 1154 & 1155 \\
\hline Pyridine ring stretch & $1068,1028,1014,993$ & $1068,1025,1014,998$ \\
\hline Pyridine-methylene rock & $749,724,697$ & $745,723,694$ \\
\hline \multicolumn{2}{|c|}{ Spatial bend } & \multicolumn{2}{|c|}{} \\
\hline \multicolumn{2}{|c|}{ Table 3. FTIR Spectral Data of Drug and Excipients } \\
\hline
\end{tabular}

\section{Drug Entrapment Efficiency (DEE)}

It was observed that the DEE was good in all the FM at the rousing of $500 \mathrm{rpm}$ (table 4). The trapping efficiency was ranged from $66.22 \pm 0.32$ to $73.73 \pm 0.95 \%$ for formulation F1 to F8. The DEE was augmented by hike the polymer concentration in FM. This may be owing to the low solubility of $\mathrm{CB}$ in water, which facilitates the diffusion of a part of the $\mathrm{CB}$ trapped in the surrounding during the preparation of the FM.

\section{Particle Size Analysis}

The size of the FM varied slightly batch to batch owing to the variation in the formula. The size of the FM is shown in table 4 The $\mathrm{F} 1$ formulation showed a relatively large percentage of large size $(294.31 \pm 8.88)$ and the F8 formulation showed fluctuating FM of relatively small size $(218.84 \pm 5.29 \mu)$ as the viscidness of the medium elevated to a higher polymer concentration, resulting in improved interfacial tension. The particle size diminutions were observed by aggressive stirring of calcium chloride solution. The FM were globular with no significant visible irregularity on the surface. The buoyancy percentage was shown in table 4.

\section{The Buoyancy Percentage}

The buoyancy rate for all the lots was almost over $70 \%$ (for 10 h). The buoyancy average as a percentage has gone from $71.04 \pm 0.64 \%$ to $89.36 \pm 5.52 \%$. The uppermost $\%$ was acquired with the formulation of F8. 


\begin{tabular}{|c|c|c|c|c|c|}
\hline $\begin{array}{c}\text { Form- } \\
\text { ulation }\end{array}$ & $\begin{array}{c}\text { Yield } \\
\mathbf{( \% )}\end{array}$ & $\begin{array}{c}\text { Particle } \\
\text { Size }(\boldsymbol{\mu})\end{array}$ & $\begin{array}{c}\text { Drug } \\
\text { Entrapment } \\
\mathbf{( \% )}\end{array}$ & $\begin{array}{c}\text { Buoyancy } \\
\text { Percentage } \\
\mathbf{( \% )}\end{array}$ & $\begin{array}{c}\text { Floating } \\
\text { Time (h) }\end{array}$ \\
\hline F1 & $54.25 \pm 1.20$ & $294.31 \pm 8.88$ & $72.21 \pm 1.20$ & $71.04 \pm 0.64$ & $4.1 \pm 0.07$ \\
\hline F2 & $62.53 \pm 1.36$ & $272.15 \pm 6.35$ & $67.95 \pm 0.35$ & $75.26 \pm 1.37$ & $4.5 \pm 0.06$ \\
\hline F3 & $74.51 \pm 2.25$ & $279.35 \pm 6.35$ & $70.19 \pm 0.68$ & $79.28 \pm 1.69$ & $3.5 \pm 0.05$ \\
\hline F4 & $79.85 \pm 5.21$ & $270.23 \pm 7.84$ & $72.25 \pm 1.35$ & $85.51 \pm 1.27$ & $5.2 \pm 0.01$ \\
\hline F5 & $62.52 \pm 1.02$ & $284.71 \pm 9.67$ & $76.47 \pm 0.69$ & $84.22 \pm 0.63$ & $9.3 \pm 0.15$ \\
\hline F6 & $78.13 \pm 2.09$ & $285.91 \pm 8.45$ & $68.55 \pm 0.54$ & $86.84 \pm 0.92$ & $7.5 \pm 0.11$ \\
\hline F7 & $68.71 \pm 0.98$ & $287.33 \pm 4.85$ & $66.22 \pm 0.32$ & $72.52 \pm 1.35$ & $8.0 \pm 0.35$ \\
\hline F8 & $65.65 \pm 2.35$ & $218.84 \pm 5.29$ & $71.06 \pm 0.64$ & $89.36 \pm 5.52$ & $9.9 \pm 0.29$ \\
\hline Values are in mean \pm SD; Trials made $=3$ \\
\hline \multicolumn{7}{|c|}{ Table 4. Efficiency of FM of Clopidogrel FM } \\
\hline \multicolumn{7}{|c|}{}
\end{tabular}

\section{Calibration Curve}

The CB concentrations were estimated by the regression equation which produced a slope (y) $0.0131 \mathrm{x}-0.0049$ and a regression $\left(R^{2}\right)$ value of 0.9899 for the calibration curve of $C B$ in $0.1 \mathrm{~N} \mathrm{HCl}$ ( $\mathrm{pH}$ 1.2). The calibration curve was found to be linear. This calibration curve was exploited for the determination of $\mathrm{CB}$ discharge from the microspheres. The calibration curve of CB was shown in figure 1.

\section{In-Vitro Dissolution Study}

The FM showed a prolonged emission of the CB in an acidic medium and the release of the $\mathrm{CB}$ was approximately linear (about $40 \%$ of $\mathrm{CB}$ was initially released). The $\mathrm{CB}$ release was observed to be slow and systematically extended for a prolonged period of time. Furthermore, the release of the $\mathrm{CB}$ from the FM matrix was regulated by the discharge retardant polymer used in the formulations. The CB discharge was detected to be unrelenting in a dawdling and unvarying pattern in the presence of ethyl cellulose. This can reduce the total DR from the polymer matrix. Moreover, the smaller FM are designed at a minor polymer level has a wider surface opened for the dissolution medium, which results in a faster DR (figure 2).

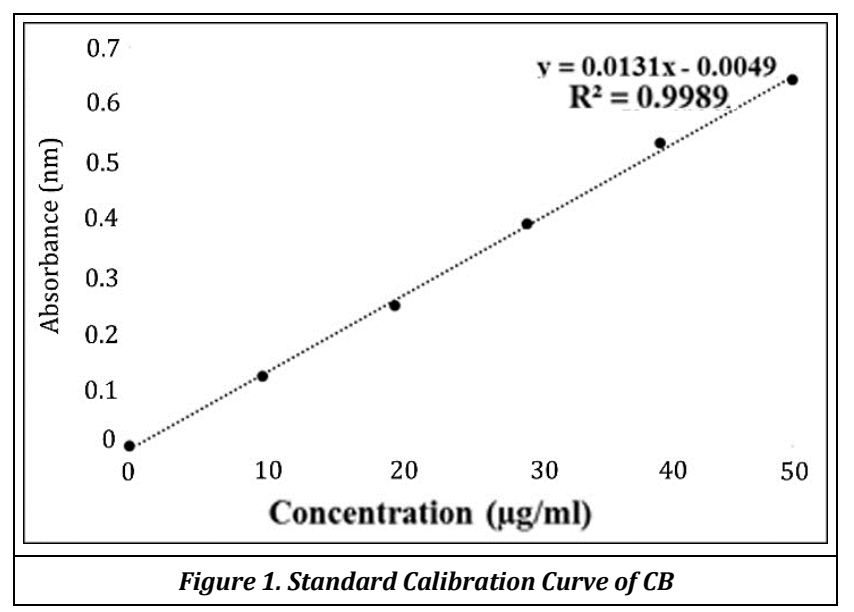

\begin{tabular}{|c|c|c|c|c|c|c|}
\hline \multirow{3}{*}{ Type } & \multicolumn{6}{|c|}{ Kinetic Data } \\
\hline & \multicolumn{2}{|c|}{ Zero Order } & \multicolumn{2}{|c|}{ First Order } & \multicolumn{2}{|c|}{ Hixson Crowell's } \\
\hline & $K\left(\min ^{-1}\right)$ & $\mathbf{R}^{2}$ & $K\left(\min ^{-1}\right)$ & $\mathbf{R}^{2}$ & $K\left(\min ^{-1}\right)$ & $\mathbf{R}^{2}$ \\
\hline F1 & 1.283 & 0.679 & 0.033 & 0.948 & 0.052 & 0.989 \\
\hline F2 & 1.160 & 0.567 & 0.019 & 0.968 & 0.045 & 0.957 \\
\hline F3 & 1.085 & 0.482 & 0.011 & 0.993 & 0.041 & 0.972 \\
\hline F4 & 1.056 & 0.471 & 0.017 & 0.979 & 0.033 & 0.978 \\
\hline F5 & 1.099 & 0.445 & 0.033 & 0.964 & 0.046 & 0.887 \\
\hline F6 & 1.095 & 0.459 & 0.035 & 0.967 & 0.043 & 0.966 \\
\hline F7 & 1.060 & 0.364 & 0.017 & 0.978 & 0.033 & 0.978 \\
\hline F8 & 1.049 & 0.356 & 0.013 & 0.918 & 0.046 & 0.889 \\
\hline
\end{tabular}

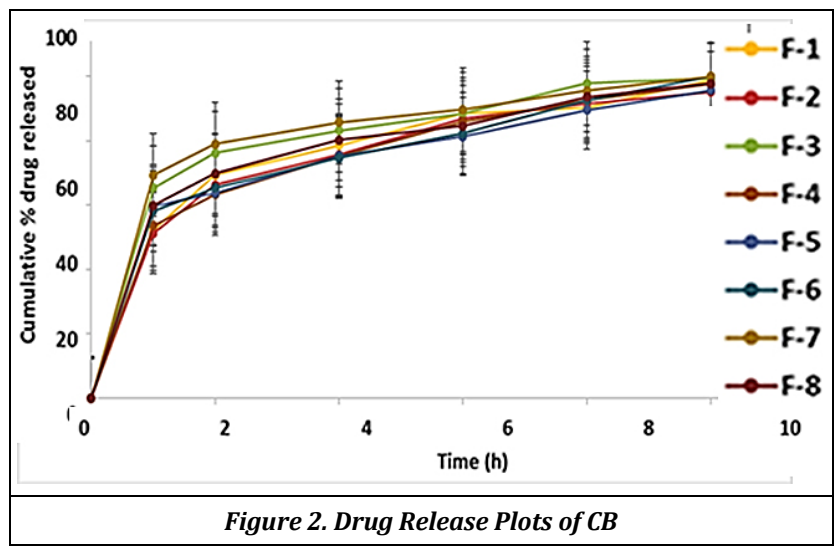

Mechanism of Release

The data gained for in-vitro discharge were snug into equalities for the zero-order, first-order and Hixson Crowell's release models to know the best fit model. The in-vitro DR showed the uppermost recession coefficient reading for Hixson Crowell's model (with the regression values ranged from 0.887 to 0.989 ), representing diffusion to be the predominant mechanism of DR from the prepared microspheres (table 5).

\section{DISCUSSION}

In this research work CB floating microspheres which were made by exfoliation technique and characterized for morphology and drug release profiles. The CB thermo gram produced a single acute endothermic started at $159.21^{\circ} \mathrm{C}$, gave an optimum peak at $157.01{ }^{\circ} \mathrm{C}$ and ended at $163.24{ }^{\circ} \mathrm{C}$, on the other hand, the $\mathrm{CB}$ mixture presented the initiation of an endothermic peak at $157.95{ }^{\circ} \mathrm{C}$, optimum at $154.53{ }^{\circ} \mathrm{C}$ and ended at $157.99^{\circ} \mathrm{C}$. These thermo grams indicated that a small change to the left when combined with excipients, this could be owing to the $\mathrm{CB}$ melting or its conversion into an amorphous form. These thermo grams indicate that there are no signs of incompatibility between $\mathrm{CB}$ and excipients.

The FTIR spectra of CB showed characteristic stretches of 'OH' group at $3450 \mathrm{~cm}^{-1}$, 'CH'- Stretch at $2954 \mathrm{~cm}^{-1}$, carboxylic (c=0) at $1752 \mathrm{~cm}^{-1}$, etc., which were also seen in FTIR spectrum of CB-excipient blend indicating no possible incompatibility of $\mathrm{CB}$ with the excipients used. It was observed that the DEE was good in all the FM at the rousing of $500 \mathrm{rpm}$. The trapping efficiency was ranged from $66.22 \pm 0.32$ to $73.73 \pm 0.95 \%$ for formulation F1 to F8. The DEE was augmented by hike the polymer concentration in FM. This may be owing to the low solubility of $\mathrm{CB}$ in water, which facilitates the diffusion of a part of the $\mathrm{CB}$ trapped in the surrounding during the preparation of the FM.

The size of the FM varied slightly among the various formulae. The F1 formulation showed a relatively large percentage of large size (294.31 \pm 8.88$)$ and the F8 formulation showed fluctuating FM of relatively small size $(218.84 \pm 5.29 \mu)$ as the viscidness of the medium elevated to a higher polymer concentration, resulting in improved interfacial tension. The particle size diminutions were observed by aggressive stirring of calcium chloride solution.

The FM were globular with no significant visible irregularity on the surface. The buoyancy rate for all the lots 
was almost over $70 \%$ (for $10 \mathrm{~h}$ ). The buoyancy average as a percentage has gone from $71.04 \pm 0.64 \%$ to $89.36 \pm 5.52 \%$. The uppermost $\%$ was acquired with the formulation of F8. The CB concentrations were estimated by the regression equation which produced a slope (y) $0.0131 \mathrm{x}-0.0049$ and a regression $\left(\mathrm{R}^{2}\right)$ value of 0.9899 for the calibration curve of $\mathrm{CB}$ in $0.1 \mathrm{~N} \mathrm{HCl}$ ( $\mathrm{pH}$ 1.2). The calibration curve was found to be linear. This calibration curve was exploited for the determination of $\mathrm{CB}$ discharge from the microspheres.

The FM showed a prolonged emission of the CB in an acidic medium and the release of the $\mathrm{CB}$ was approximately linear (about $40 \%$ of CB was initially released). The CB release was observed to be slow and systematically extended for a prolonged period of time. Furthermore, the release of the CB from the FM matrix was regulated by the discharge retardant polymer used in the formulations. The $\mathrm{CB}$ discharge was detected to be unrelenting in a dawdling and unvarying pattern in the presence of ethyl cellulose. This can reduce the total DR from the polymer matrix. Moreover, the smaller FM are designed at a minor polymer level has a wider surface opened for the dissolution medium, which results in a faster DR.

The in-vitro DR showed the uppermost recession coefficient reading for Hixson Crowell's model (with the regression values ranged from 0.887 to 0.989 ), representing diffusion to be the predominant mechanism of DR from the prepared microspheres.

\section{CONCLUSIONS}

The study summarizes and confirms the compatibility of clopidogrel bisulphate (CB) with the polymers used. The invitro data obtained from the prepared floating microspheres (FM) of CB displayed good incorporation effectiveness, appreciable buoyancy, and lengthy drug release in a controlled manner. The microspheres of different sizes and CB content could be attained by fluctuating the ingredients. The in-vitro DR from the prepared from the CB microspheres revealed that the Hixson Crowell's model is best fitted to the CB release from the prepared microspheres. This experiment concludes that CB can be formulated as FM using sodium alginate, ethyl cellulose and carrageenan gum by ionotropic gelation method. The FM disclosed a better suitable balance amid buoyancy and CB discharge.

\section{ACKNOWLEDGEMENT}

The authors thank Apotex, Bangalore, for sending the drug sample of Clopidogrel Bisulphate.

\section{REFERENCES}

[1] Ahad HA, Kumar CS, Reddy KK, et al. Novel approach in ranitidine hydrochloride effervescent oral floating technique. J Pharmacy Research 2011;4(1):104-6.

[2] David E, Armen HT, Ethrin JA, et al. Principles of pharmacology. The pathophysiologic basis of drug therapy. $2^{\text {nd }}$ edn. New Delhi: Wolters Kluwer (India) Pvt. Ltd., 2008: p. 815.

[3] Jagadeesh KD, Hindustan AA, Anuradha CM, et al. Dual acting oral floating matrix tablets of ranitidine Hydrochloride. Int J of Applied Biology and Pharm Tech 2010;1(2):602-7.

[4] Hindustan AA, Babu UA, Nagesh K, et al. Fabrication of glimepiride $<\mathrm{i}>$ Datura Stramonium $</$ i $>$ leaves mucilage and polyvinyl pyrrolidone sustained release matrix tablets: <i> Invitro</i\&gt; evaluation. Kathmandu University J Sci Eng Tech 2012;8(1):63-72.

[5] Londhe S, Gattani S, Surana S. Development of floating drug delivery system with biphasic release for Verapamil hydrochloride: Invitro and In-vivo evaluation. J Pharm Sci Tech 2010;2(11):361-7.

[6] Sharma N, Agarwal D, Gupta MK, et al. A comprehensive review on floating drug delivery system. International Journal of Research in Pharmaceutical and Biomedical Sciences 2011;2(2):428-41.

[7] Rathod H, Patel V, Modasia M. Floating drug delivery system: innovative approach of gastroretention. International Journal of Pharmaceutical Sciences Review and Research 2010;4(3):183-92.

[8] Dixit N. Floating drug delivery system. Journal of Current Pharmaceutical Research 2011;7(1):6-20.

[9] Nakagawa M, Kondo SC, Sasai Y, et al. Preparation of floating drug delivery system by plasma technique. Chemical and Pharmaceutical Bulletin (The Pharmaceutical Society of Japan) 2006;54(4):514-8.

[10] Dorozynski P, Kulinowski P, Jachowicz R, et al. Development of a system for simultaneous dissolution studies and magnetic resonance imaging of water transport in hydrodynamically balanced systems: a technical note. AAPS Pharm Sci Tech 2007;8(1):E109-E2.

[11] Hemanth A, Hindustan AA, Devanna N. Evaluating the best polyethylene glycol as solid dispersion carrier by taking Etoricoxib as a model drug. Asian J Pharm Clin Res 2019;12(3):250-5.

[12] Annepogu H, Abdul HA, Nayakanti D. Appraising best poly ethylene glycol carrier for thiocolchicoside solid dispersions. J Pharm Chem Biol Sci 2019;6(4):355-64.

[13] Jain A. New concept: floating drug delivery system. Indian Journal of Novel Drug Delivery 2011;3(3):162-9. 